\title{
Ozone profiling using kites
}

SIR - An innovative technique for profiling ozone concentration in the lower atmosphere was begun last August as part of the North Atlantic Regional Experiment (NARE) campaign in Nova Scotia. The technique involved repeatedly transporting a conventional ozonesonde package up and down the tether of a high-tech kite 'platform' stationed at altitudes up to a few kilometres. This technique enabled us to obtain a rapid series of vertical profiles of temperature, pressure, humidity and ozone concentration using the same sonde package.

Although kites have been used for atmospheric research since the mid-1700s, their potential as research tools has been improved substantially by the advent of lightweight, high-strength materials such as Kevlar (for tethers) and Mylar (for kites) (B. B. Balsley et al. Bull. Am. Met. Soc. 73, 17-29; 1992). The NARE kite system consisted of a $15 \mathrm{~m}^{2}$ cross-section Mylar kite, a 7,500-m reel of $280 \mathrm{~kg}$ test Kevlar, a gasoline-powered hydraulic winch, a payload consisting of a conventional Vaisala-sonde (temperature, press-

\section{Cape Sable Island, N.S.}

Ascent (12:35:17 - 15:54:21 ADT)

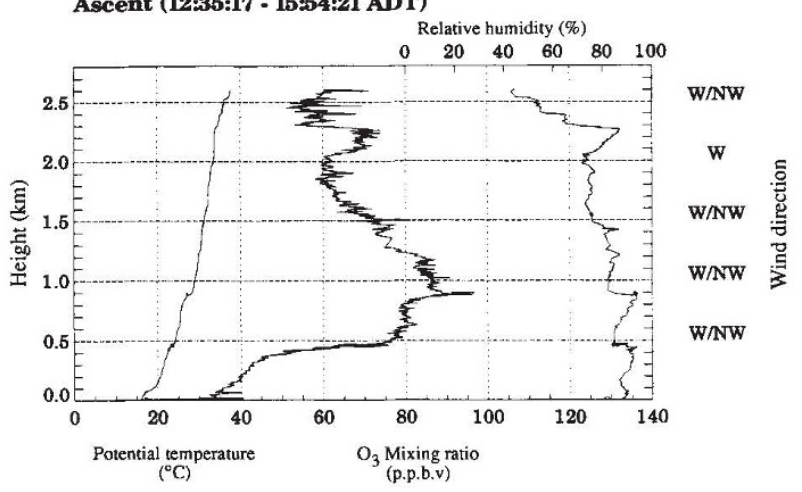

Descent (15:54:21 - 19:13:41 ADT

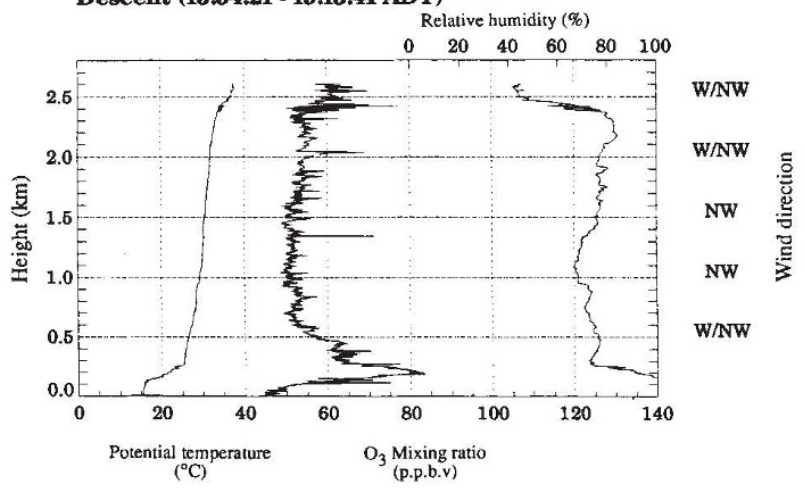

Profiles of temperature, humidity and ozone mixing ratio obtained by connecting the ozonesonde directly to the tether and reeling the kite out ( $a$, ascent profiles) and back in ( $b$, descent profile). As indicated, these two profiles took roughly $3 \mathrm{~h}$ each to measure, and are separated in time by about the same amount. Approximate wind directions appear to the right. ure and humidity) coupled to a Science Pump Corporation ozonesonde, and our WindTRAM (see below). The total system weight was approximately $32 \mathrm{~kg}$.

A specially designed WindTRAM (Tethered Rover for Atmospheric Measurements) transported the ozonesonde payload up and down the tether. The TRAM (photograph) comprised a $1-\mathrm{m}^{2}$ wind-driven device attached to the tether via a long cylindrical tube, and provided sufficient lift to loft approximately 5-kg payloads rapidly from the ground to the kite. The TRAM was brought down either by radio command from the ground station, or by a mechanical release that operated if the TRAM approached too close to the kite itself.

Two sets of kite-borne profiles are presented in the figure. Examination of this figure shows the excellent height resolution available from the kite-borne technique. The narrow $(20 \mathrm{~m})$ enhanced layer at about $850 \mathrm{~m}$ in the first profile exemplifies this capability. Note also the associated 'kink' in the potential temperature profile and structure in the humidity profile at the same height.

A strong temporal variability of the ozone profile can be inferred by intercomparing these two profiles, which were separated by about $3 \mathrm{~h}$. The enhanced ozone concentration lying between roughly 500 and $1,500 \mathrm{~m}$ has all but disappeared by the time the sonde has retraced through the region about $3 \mathrm{~h}$ later. Since the time to make each profile is comparable to the time separation between profiles, it is apparent that neither of these profiles represents a true instantaneous profile. Much higher time resolution is needed to determine the time evolution of the profiles. This require- ment is well within the capability of the WindTRAM, which has a measured rise rate at least an order of magnitude larger than that used in the current examples.

We obtained about 40 profiles of temperature, pressure, humidity and

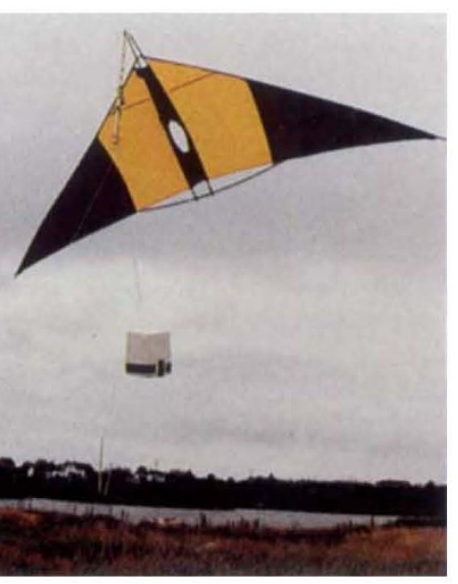

WindTRAM connected to the kite tether. The while the kite remains aloft.

ozone concentration between 8 and 29 August 1993. During this period, the measured ozone concentration aloft depended strongly on the direction of the prevailing wind. The largest values were obtained when the wind was coming from the west, from the northeastern United States. Note that values aloft were not well correlated with concurrent groundbased values; it was not uncommon for the ground-level mixing ratio of ozone to be $20-40$ p.p.b.v., while mixing ratios above about $300 \mathrm{~m}$ were in the $90-130$ p.p.b.v. range.

These results underscore the practicality of the reuse of conventional ozonesondes using a kite-borne technology. Perhaps of greater importance is the demonstrated feasibility of reasonably continuous profiling of any number of atmospheric constituents using reusable sondes carried aloft by this technology. Primary requirements are that the instrumentation be lightweight (a few $\mathrm{kg}$ ) and consume minimal power (a few watts). Finally, our theoretical studies suggest the possibility of kite profiling into the lower stratosphere.

Ben B. Balsley

John W. Birks

Michael L. Jensen

Karl G. Knapp

Cooperative Institute for Research in the

Environmental Sciences,

Campus Box 216 ,

University of Colorado,

Boulder, Colorado 80309-0216, USA

Joseph B. Williams

G. William Tyrrell

Modelsym, Inc.,

Gereau Building,

Doylestown,

Pensylvannia 18901, USA 